\title{
Generic versus branded enoxaparin in prophylaxis and treatment of vein thrombosis
}

\author{
ivan Benaduce Casella ${ }^{1 *}$, Pedro Puech-Leão² \\ ${ }^{1}$ Physician and Collaborating Professor, Faculty of Medicine, University of São Paulo (FMUSP), São Paulo, SP, Brazil \\ ${ }^{2}$ Full Professor, Vascular Surgery, FMUSP, São Paulo, SP, Brazil
}

Study conducted by the Department of Vascular and Endovascular Surgery FMUSP (São Paulo)

Article received: $5 / 7 / 2014$ Accepted for publication: 6/3/2014

*Correspondence: Address: Rua Dr. Ovídio Pires de Campos, 225 - PAMB $6^{\text {th }}$ floor, Block 5 Cerqueira César

Postal code: 05403-010 São Paulo - SP - Brazil ivancasel@uol.com.br

http://dx.doi.org/10.1590/1806-9282.61.01.044

Financial support: The research was funded by Aspen Labs. The authors did not receive financial support for the authorship or publication of this article.

Conflict of interest: none

\section{SUMMARY}

Objectives: to compare the biological efficacy of generic enoxaparin (Heptron ${ }^{\mathrm{TM}}$ ) versus branded Sanofi-Aventis enoxaparin for prophylaxis and treatment of lower-extremity deep venous thrombosis (DVT) in a prospective, randomized, openlabel study.

Methods: patients with diagnosed lower-extremity DVT (therapeutic branch, $\mathrm{n}=57$ ) and patients requiring venous thromboembolism (VTE) prophylaxis after arterial vascular surgery or major lower-extremity amputations (prophylactic branch, $n=57$ ) were randomized to receive generic or branded enoxaparin for up to seven days. Enoxaparin activity was measured by estimating blood anti-factor Xa levels at the peak plasma concentration. As secondary outcomes, development or progression of VTE events, major adverse events and major bleeding events were considered for efficacy and safety comparisons.

Results: DVT therapy: twenty-five patients received generic enoxaparin while 32 received branded enoxaparin (subcutaneous, $1 \mathrm{mg} / \mathrm{kg}$ BID). Mean percentages of anti-factor Xa levels within the target ranges were $62 \pm 35.4 \%$ and $67.5 \pm 24.7 \%$, respectively ( $\mathrm{p}=.035$ for non-inferiority). No patient presented DVT progression, clinically detectable pulmonary embolism, or major bleeding events in any subgroup. DVT prophylaxis: Thirty patients received generic enoxaparin and $27 \mathrm{re}-$ ceived branded enoxaparin (subcutaneous, $40 \mathrm{mg} /$ day). Mean percentages of anti-factor Xa levels within the target ranges were $77.9 \pm 30.9 \%$ and $77.8 \pm 32.9 \%$, respectively ( $\mathrm{p}=.009$ for non-inferiority). There were no cases of VTE or major bleeding events in any subgroup.

Conclusion: generic and branded enoxaparins exhibited similar in vivo responses as measured by the anti-factor Xa activity, as well as similar clinical efficacy and safety outcomes.

Keywords: enoxaparin, controlled clinical trial, biosimilar pharmaceuticals.

\section{INTRODUCTION}

Low-molecular-weight heparins (LMWH) are a class of antithrombotic drugs that are widely used for the prophylaxis and treatment of deep venous thrombosis (DVT). Meta-analyses have confirmed that LMWH shows superior efficacy to unfractionated heparin for the prevention and treatment of DVT. ${ }^{1,2}$ The pharmacologic properties of LMWH enable longer intervals between doses and provide more predictable plasma concentrations, diminishing the need for laboratory monitoring.

In recent years, bioequivalent (also described as 'generic') preparations of LMWH have been introduced to the market, leading to cost reductions and increased access to this class of drugs. ${ }^{3}$ However, unlike purely chemical generic drugs, LMWHs comprise a variable pool of similar molecules from biological origin within an expected range of molecular weights that may differ between manufacturers or even among batches from a single manufacturer.

Due to a possible variability among preparations, it is recommended that bioequivalent $\mathrm{LMWH}$ preparations should be subjected to clinical investigations to confirm their biological activities. Heptron ${ }^{\mathrm{TM}}$ is a bioequivalent enoxaparin preparation that is produced by Aspen Pharma (Cerra, ES, Brazil). 


\section{Objectives}

The primary objective of this study was to compare the in vivo biological efficacy of generic enoxaparin (Heptron $^{\mathrm{TM}}$, Aspen Pharma; hereafter generic enoxaparin) with that of a branded preparation of enoxaparin $\left(\right.$ Clexane $^{\mathrm{TM}}$ or Lovenox ${ }^{\mathrm{TM}}$; Sanofi-Aventis; hereinafter, branded enoxaparin) for prophylaxis and treatment of lower-limb DVT by estimating blood anti-factor Xa levels measured at peak plasma enoxaparin concentration. Secondary outcomes included the clinical efficacy and safety of each preparation used for prophylaxis and treatment of DVT.

\section{Methods}

\section{Study design and patients}

The study was designed as a single-center, prospective, randomized open-label study of patients who received enoxaparin for prophylaxis or treatment of lower-limb DVT. The study was approved by the local ethics committee and all patients included signed informed consent forms.

Patients who received enoxaparin for treatment of DVT had ultrasound-confirmed diagnosis of lower-limb DVT, and had no contraindications to full anticoagulation or heparin. Patients with both proximal (87.7\%) and distal DVT were included. Patients given enoxaparin for prophylaxis had vascular diseases and were at high risk of developing venous thromboembolism (VTE) after major vascular surgery (open or endovascular aortic aneurism repair, aortoiliac and infrainguinal bypass graft surgeries, infrainguinal endovascular revascularizations and major amputations). These patients had no contraindications to prophylactic anticoagulation or heparin.

Patients with grade II-III obesity (body mass index $\geq 35 \mathrm{~kg} / \mathrm{m}^{2}$ ) or advanced chronic renal insufficiency (estimated creatinine clearance $\leq 30 \mathrm{~mL} / \mathrm{min}$ ) were excluded from this study.

Patients in the prophylaxis and treatment groups were randomly allocated into two subgroups to receive either generic or branded enoxaparin. The sample size was initially calculated based on the primary outcome and was estimated to be 120 patients (considering a maximum of $15 \%$ post-randomization exclusion rate), with 60 individuals included in each of the prophylaxis and treatment groups, and 30 patients randomized to each drug.

\section{Procedures}

After randomization, patients in the treatment group received a subcutaneous injection of $1 \mathrm{mg} / \mathrm{kg}$ of the allocated type of enoxaparin twice daily (usually at 9 a.m. and 9 p.m.). Blood samples were collected daily approximately 4 hours after administration of the morning dose of enoxaparin, corresponding to the expected peak plasma concentration, ${ }^{4}$ to determine anti-factor Xa activity. Oral warfarin was generally started on day 1 or 2 of enoxaparin administration at an initial daily dose of $5 \mathrm{mg}$, and was adjusted according to the prothrombin time/international normalized ratio (INR) value. Patients received enoxaparin until their INR reached 2-3 and were then discharged. Anti-factor Xa levels were measured during this period or for up to 7 days.

Similar procedures were used in the prophylaxis group, except for the different LMWH dose of $40 \mathrm{mg}$ once daily (usually at 9 a.m.). These patients were not given warfarin and they were followed until discharge or for up to 7 days. Prophylaxis was generally started 1-2 days after surgery, at the surgeon's discretion.

All patients were clinically evaluated every day to assess the evolution of DVT, to identify possible signs/symptoms of pulmonary embolism, and to detect hemorrhagic and non-hemorrhagic adverse events. All patients underwent Doppler ultrasound (DU) on the first and last days of the study period. In the treatment group, DU was performed to confirm the diagnosis of DVT and to determine whether the extent of thrombosis had progressed at discharge. In the prophylactic group, DU was performed to confirm the absence of DVT at the start and end of the study period.

Anti-factor Xa activity was determined using a chromogenic assay (TriniCHROM Heparin; Tcoag Laboratories, Wicklow, Ireland).

Hemoglobin and hematocrit levels, platelet count and creatinine levels were obtained on a daily basis in all patients to detect signs of occult blood loss, heparin-induced thrombocytopenia, renal function impairment or other possible complications.

\section{Anti-factor Xa outcomes}

The desired ranges of anti-factor Xa levels were 0.2-0.6 U/ $\mathrm{mL}$ for prophylaxis ${ }^{5,6}$ and $0.6-1.0 \mathrm{U} / \mathrm{mL}$ for treatment based on calibrated values in our clinical laboratories and according to the values used in a prior study. ${ }^{4}$ The percentage of anti-factor Xa measurements within the desired ranges was calculated for each patient by dividing the number of anti-factor Xa measurements within the desired range by the total number of measurements for the individual patient.

\section{Clinical outcomes}

In the treatment group, clinical efficacy was defined as the absence of worsening of DVT symptoms, absence of thrombotic progression, and absence of clinically detec- 
table pulmonary embolism. In the prophylaxis group, clinical efficacy was defined as the absence of DVT and/or clinically detectable pulmonary embolism.

Safety was defined as the absence of spontaneous bleeding after starting enoxaparin, the absence of heparin-induced thrombocytopenia, and the absence of adverse events that could be attributed to enoxaparin.

\section{Statistical analysis}

Chi-square/Fisher's test was used to compare categorical variables and Mann-Whitney $U$ test was used to compare quantitative variables between generic and branded enoxaparin. Values of $\mathrm{p}<0.05$ were considered statistically significant. Non-inferiority of generic enoxaparin for the primary outcome was tested using unilateral hypothesis (z) test.

\section{RESULTS}

\section{Patient distribution}

Sixty-four patients were initially randomized for DVT prophylaxis and 56 for DVT therapy. The distribution of patients is detailed in Table 1. Five patients in the prophylaxis group were removed from the study after randomization but before receiving a dose of enoxaparin, due to acute worsening of renal function 1-2 days after surgery $(n=4)$ or a higher dose of enoxaparin being requested by the surgeon $(n=1)$. These patients were not included in the statistical analyses. One patient in the prophylaxis group withdrew informed consent after one dose of enoxaparin and was not included in statistical analyses. One patient in the prophylaxis group was randomized, but was diagnosed with calf DVT by ultrasound immediately after surgery. Since enoxaparin had not been administered before detection of DVT, this patient was transferred to the treatment group. All of the patients in the prophylaxis group had Caprini scores $\geq 5$ (mean 8.77, range 5-11), representing high risk of developing VTE.

Serious adverse events (SAE) occurred in 14 patients, five occurring previous to enoxaparin administration. All affected patients were from the prophylactic group and in nine cases, SAE led to early interruption of the protocol or patient withdrawal before administering enoxaparin. The most common SAE was acute postoperative worsening of renal function (4 cases) but there was also clinical worsening of chronic limb ischemia (2), transitory cognitive impairment (2), paralytic ileus, wound infection, decrease in hemoglobin levels, suspicion of pseudoaneurysm (unconfirmed), arterial thrombosis (limb).

\section{DVT prophylaxis}

Fifty seven patients received enoxaparin for prophylaxis, with 30 allocated to generic and 27 to branded enoxaparin. Sex distribution, age, and clinical characteristics of both subgroups were similar (Table 1). The surgical procedures performed are summarized in Table 2. The mean anti-factor Xa levels were $0.28 \pm 0.15 \mathrm{U} / \mathrm{mL}$ and $0.26 \pm$ $0.12 \mathrm{U} / \mathrm{mL}$ in the generic and branded enoxaparin subgroups, respectively $(\mathrm{p}=.83$, Table 3$)$. The mean percentages of anti-factor Xa levels within the target ranges were $77.9 \pm 30.9 \%$ and $77.8 \pm 32.9 \%$, respectively ( $\mathrm{p}=.009$ for non-inferiority, Table 3). As shown in Figure 1, the mean daily variation in anti-factor Xa levels was not significantly different between the two subgroups of patients.

None of the patients in either group developed DVT or clinically detectable pulmonary embolism. DU performed before discharge confirmed the absence of DVT in

TABLE 1 Clinical and epidemiological characteristics of patients

\begin{tabular}{|c|c|c|c|c|c|c|}
\hline & \multicolumn{2}{|l|}{ Prophylaxis group } & \multirow[t]{2}{*}{$\mathbf{p}$} & \multirow{2}{*}{$\begin{array}{l}\text { Treatment group } \\
\text { Branded enoxaparin } \\
n=32\end{array}$} & \multirow[b]{2}{*}{$\begin{array}{l}\text { Generic enoxaparin } \\
n=25\end{array}$} & \multirow[t]{2}{*}{$\mathbf{p}$} \\
\hline & $\begin{array}{l}\text { Branded enoxaparin } \\
n=27\end{array}$ & $\begin{array}{l}\text { Generic enoxaparin } \\
n=30\end{array}$ & & & & \\
\hline Male sex, n (\%) & $21(77.8 \%)$ & $25(83.3 \%)$ & 0.84 & $17(53.1 \%)$ & $10(40.0 \%)$ & 0.47 \\
\hline Age, years & $66.9 \pm 10.2$ & $67.0 \pm 6.2$ & 0.94 & $49.9 \pm 16.3$ & $47.9 \pm 18.8$ & 0.67 \\
\hline Left limb DVT, n (\%) & & & & $17(53.1 \%)$ & $16(64.0 \%)$ & 0.57 \\
\hline Proximal DVT, n (\%) & & & & $28(87.5 \%)$ & $22(88.0 \%)$ & 0.67 \\
\hline Caprini score $\geq 5, \mathrm{n}(\%)$ & $27(100.0 \%)$ & $30(100.0 \%)$ & & & & \\
\hline Weight, kg & $72.5 \pm 13.5$ & $67.3 \pm 14.7$ & 0.10 & $74.1 \pm 13.0$ & $68.5 \pm 17.8$ & 0.08 \\
\hline BMI, kg/m² & $26.2 \pm 3.8$ & $24.5 \pm 4.4$ & 0.08 & $26.5 \pm 4.22$ & $24.8 \pm 4.97$ & 0.16 \\
\hline Creatinine (mg/dL) & $1.04 \pm 0.32$ & $0.99 \pm 0.27$ & 0.72 & $0.88 \pm 0.24$ & $0.84 \pm 0.27$ & 0.46 \\
\hline Creatinine clearance (\%) & $73.1 \pm 23.3$ & $69.7 \pm 24.1$ & 0.35 & $103.6 \pm 38.7$ & $100.0 \pm 31.7$ & 0.89 \\
\hline
\end{tabular}

DVT: deep vein thrombosis; BMI: body mass index. Values are means \pm standard deviation or $\mathrm{n}(\%)$. 


\section{TABLE 2 Surgeries performed in patients from the prophylactic group}

\begin{tabular}{l|l|l|l|l} 
& \multicolumn{2}{l}{ N (\%) } & \multirow{P}{*}{} & \multirow{2}{*}{ Overall Frequency (\%) } \\
\hline Subgroups & Generic & Branded & & \\
\hline Infrainguinal bypass graft & $10(58.8)$ & $7(41.2)$ & .74 & $17(29.8)$ \\
\hline Aortoiliac bypass graft & $9(56.3)$ & $7(43.8)$ & .96 & $16(28.1)$ \\
\hline EVAR & $4(50.0)$ & $4(50.0)$ & .82 & $08(14.0)$ \\
\hline Major amputations & $4(57.1)$ & $3(42.9)$ & .88 & $07(12.3)$ \\
\hline Infrainguinal PTA & $2(33.3)$ & $4(66.7)$ & .56 & $06(10.5)$ \\
\hline Other & $1(33.3)$ & $2(66.7)$ & .92 & $03(5.3)$ \\
\hline
\end{tabular}

EVAR: endovascular aortic aneurism repair; PTA: percutaneous transluminal angioplasty.

TABLE 3 Comparison of the results between generic and branded enoxaparin

\begin{tabular}{|c|c|c|c|c|c|c|}
\hline & \multicolumn{2}{|c|}{ Prophylaxis group } & \multicolumn{2}{|c|}{ Treatment group } & \multicolumn{2}{|l|}{ All patients } \\
\hline & $\begin{array}{l}\text { Branded } \\
\text { enoxaparin }\end{array}$ & $\begin{array}{l}\text { Generic } \\
\text { enoxaparin }\end{array}$ & $\begin{array}{l}\text { Branded } \\
\text { enoxaparin }\end{array}$ & $\begin{array}{l}\text { Generic } \\
\text { enoxaparin }\end{array}$ & $\begin{array}{l}\text { Branded } \\
\text { enoxaparin }\end{array}$ & $\begin{array}{l}\text { Generic } \\
\text { enoxaparin }\end{array}$ \\
\hline$n$ & 27 & 30 & 32 & 25 & 59 & 55 \\
\hline Total number of doses administered & 119 & 141 & 344 & 256 & 463 & 397 \\
\hline Doses/patient (mean) & 4.4 & 4.7 & 10.7 & 10.2 & 7.8 & 7.2 \\
\hline $\mathrm{p}$ & \multicolumn{2}{|l|}{0.51} & \multicolumn{2}{|l|}{0.39} & & \\
\hline $\begin{array}{l}\text { Percentage of anti-factor Xa } \\
\text { measurements within the desired } \\
\text { target range }\end{array}$ & $77.8 \pm 32.9$ & $77.9 \pm 30.9$ & $67.5 \pm 24.7$ & $62.0 \pm 35.4$ & $72.2 \pm 29.0$ & $70.7 \pm 33.7$ \\
\hline $\mathrm{p}$ & \multicolumn{2}{|l|}{0.87} & \multicolumn{2}{|l|}{0.87} & & \\
\hline 95\% Cl for non-inferiority* & -14.276 to 14.039 & -7.787 to 18.893 & & & & \\
\hline p for non-inferiority* & \multicolumn{2}{|l|}{0.009} & \multicolumn{2}{|l|}{0.035} & & \\
\hline Mean anti-factor Xa level, $\mathrm{U} / \mathrm{mL}$ & $0.26 \pm 0.12$ & $0.28 \pm 0.15$ & $0.74 \pm 0.18$ & $0.71 \pm 0.23$ & $\mathrm{~N} / \mathrm{A}$ & $\mathrm{N} / \mathrm{A}$ \\
\hline $\mathrm{p}$ & \multicolumn{2}{|l|}{0.83} & \multicolumn{2}{|l|}{0.79} & & \\
\hline VTE development & $0 / 27$ & $0 / 30$ & $\mathrm{~N} / \mathrm{A}$ & $\mathrm{N} / \mathrm{A}$ & & \\
\hline DVT progression & $\mathrm{N} / \mathrm{A}$ & $\mathrm{N} / \mathrm{A}$ & $0 / 32$ & $0 / 35$ & & \\
\hline Clinically detectable PE & $0 / 27$ & $0 / 30$ & $0 / 32$ & $0 / 35$ & & \\
\hline Major bleeding & $0 / 27$ & $0 / 30$ & $0 / 32$ & $0 / 35$ & & \\
\hline $\begin{array}{l}\text { Major adverse events (after first dose } \\
\text { administration) }\end{array}$ & $3 / 27$ & $6 / 30$ & $0 / 32$ & $0 / 35$ & & \\
\hline
\end{tabular}

$\mathrm{Cl}$ : confidence interval; N/A: not applicable; VTE: venous thromboembolism; DVT: deep venous thrombosis; PE: pulmonary embolism. Values are means \pm standard deviation.

*Non-inferiority was examined for the percentage of anti-factor Xa measurements within the target range. 


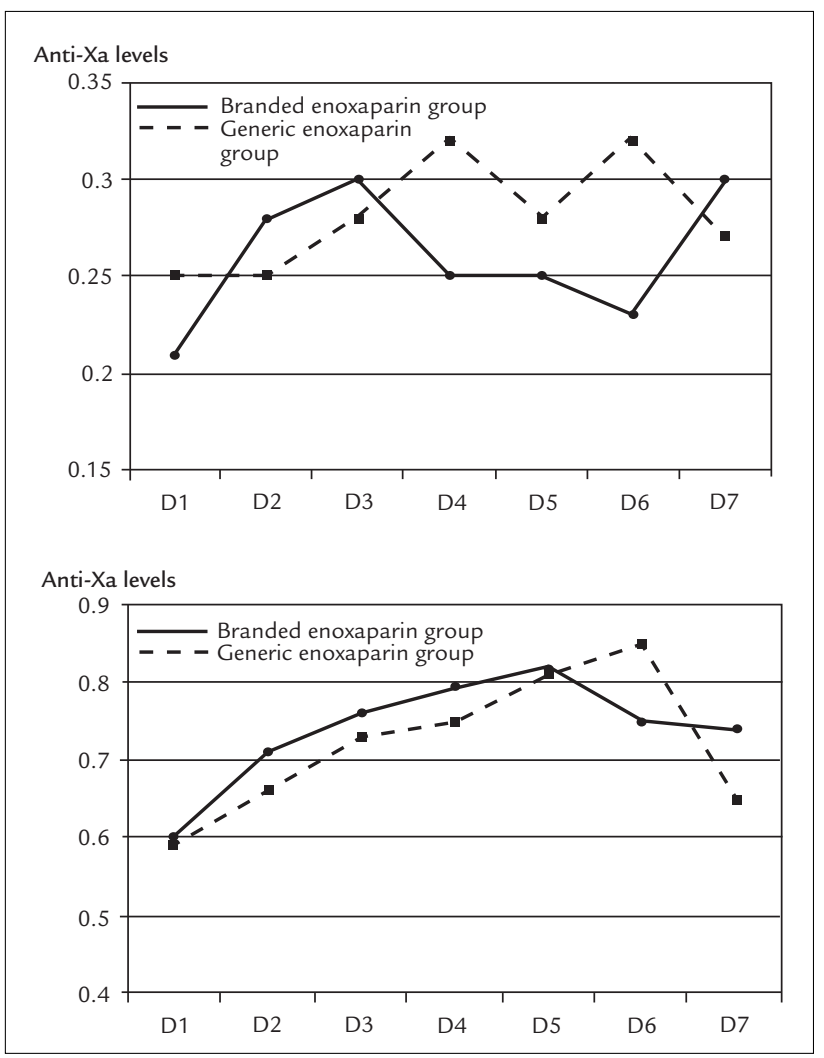

FIGURE 1 Mean daily variation in anti-factor Xa levels for patients under prophylactic (above) and therapeutic (below) regimens.

all of the patients. Furthermore, none of the patients experienced major or minor bleeding, or heparin-induced thrombocytopenia.

There were nine SAE after the first dose of any of the enoxaparins was administered, of which four required discontinuation of enoxaparin administration (2 for each subgroup). Only one event, in a patient treated with branded enoxaparin was considered possibly related to the study drug (a fall in hemoglobin levels without clinical or radiological evidence of bleeding). The occurrence of SAEs was not significantly different $(\mathrm{p}=.57)$ between the two subgroups.

\section{DVT treatment}

Fifty seven patients were enrolled in the treatment group, with 25 randomized to generic and 32 to branded enoxaparin, respectively. Sex distribution, age, and clinical characteristics were similar in both subgroups (Table 1). The clinical results in both subgroups are presented in Table 3. The mean anti-factor Xa levels were $0.71 \pm 0.23 \mathrm{U} / \mathrm{mL}$ and $0.74 \pm 0.18 \mathrm{U} / \mathrm{mL}$ in the generic and branded subgroups, respectively $(\mathrm{p}=.79)$. The mean percentages of anti-factor Xa levels within the target range were $62.0 \% \pm$
$35.4 \%$ and $67.5 \% \pm 24.7 \%$, respectively ( $\mathrm{p}=.035$ for non-inferiority). As shown in Figure 1, the mean daily variation in anti-factor Xa levels was not significantly different between the two subgroups of patients.

None of the patients in either subgroup showed worsening of DVT symptoms or clinically detectable pulmonary embolism. DU performed before discharge revealed no evidence of thrombus progression in any patient. There were no cases of major or minor bleeding, or heparin induced-thrombocytopenia. Additionally, there were no serious adverse events in any patient of the therapeutic group.

\section{Discussion}

Many in vitro and/or pharmacologic/pharmacokinetic studies have been performed to compare branded and generic enoxaparin preparations. However, very few clinical studies have been conducted to compare such drugs. To our knowledge, only two clinical studies have compared generic and branded enoxaparin preparations for preventing VTE in high-risk patients.

Gomes et al. ${ }^{9}$ compared branded enoxaparin (Sanofi-Aventis) and generic enoxaparin for VTE prophylaxis in 170 patients undergoing abdominal surgery, and reported that the two preparations had similar efficacy and safety profiles. Lage et al. ${ }^{10}$ also compared branded and generic LMWH for prophylaxis and treatment in intensive care unit patients, with clinical efficacy and safety being the main outcomes. Anti-factor Xa levels were also compared as a secondary outcome, but not every day. In the study by Lage et al., ${ }^{10}$ VTE prophylaxis was generally indicated for clinical conditions rather than postoperative states. The efficacy and safety profiles of both preparations in that study were similar.

To our knowledge, the present study was the first to determine daily variations in anti-factor Xa levels, and the only one to include individuals using enoxaparin, both for postoperative prophylaxis of VTE and treatment of DVT.

There are many reasons why we chose anti-factor Xa activity as the primary outcome in this study. First, it reflects the biological response of the coagulation system to enoxaparin, independently of the clinical indication or the patient's clinical status. Second, it is a more sensitive marker for the drug's biological activity compared with clinical evaluation, particularly because many patients with inappropriate anti-factor Xa levels will not necessarily experience development or progression of VTE, or hemorrhagic events. Anti-factor Xa levels were measured 562 times in the present study, providing a solid base for the biological comparisons of drug responses. 
Nevertheless, anti-factor Xa levels should be considered as a surrogate marker for the clinical response to LMWH therapy. Bara et al. ${ }^{11}$ found that anti-factor Xa activity did not predict the development or progression of VTE. It must be kept in mind that the objective of measuring anti-factor Xa levels is to facilitate dose adjustment and to optimize the risk/benefit of LMWH, since bleeding and VTE are influenced by multiple factors and may occur despite optimal antithrombotic therapy.

Candidates for vascular surgeries generally present with very high risk of $\mathrm{VTE}^{12}$ because they commonly have multiple risk factors, including poor mobility, lengthy post-operative recovery time, advanced age, chronic obstructive pulmonary disease and cardiovascular disease. Even non-arterial procedures with short procedural times, such as below and above-knee amputations, are associated with a high incidence of DVT in the stump or contralateral limb, with a cumulative rate of $28 \%$ in 35 days, in the absence of pharmacological prophylaxis. ${ }^{13}$ In the present study, all of the patients in the prophylaxis group had Caprini scores of $\geq 5$, corresponding to high risk of developing VTE.

Once the sample size was estimated for the antifactor-Xa comparison, the clinical efficacy and safety outcomes must be interpreted with caution. None of the patients in the treatment group showed thrombus progression after starting enoxaparin or clinical signs of pulmonary embolism. Furthermore, none of the patients developed major bleeding or SAEs that could be clearly attributed to the treatment received. However, in the prophylaxis group, the short follow-up time (up to 7 days) limited our ability to evaluate the incidence of postoperative VTE in this patient population.

Although no immunologic tests were performed to determine heparin-induced thrombocytopenia, there were no marked decreases in daily platelet counts suggestive of heparin-induced thrombocytopenia in any patient, nor were there any clinical signs or symptoms of this complication.

In the present investigation, we performed DU to confirm the clinical outcomes in both groups. We think that DU was particularly important in the prophylaxis group, because it identified one patient who developed DVT before starting enoxaparin, allowing this patient to be re-allocated to the treatment group. Furthermore, lower limb color duplex examination immediately after stopping enoxaparin administration is an accurate method to confirm the efficacy of prophylaxis.

\section{Conclusion}

The generic and branded enoxaparin preparations used in the present study exhibited similar values of anti-factor Xa levels along the study period, in patients administered with prophylactic enoxaparin to prevent postoperative VTE and in patients administered with enoxaparin to treat DVT.

\section{Resumo}

Enoxaparina genérica versus padrão-ouro na terapia e profilaxia de trombose venosa.

Objetivos: comparar a eficácia biológica da enoxaparina genérica (Heptron ${ }^{\mathrm{TM}}$ ) versus enoxaparina Sanofi-Aventis na profilaxia e no tratamento da trombose venosa profunda (TVP) de membros inferiores em ensaio prospectivo, randomizado e não cego.

Método: pacientes com diagnóstico de TVP de membros inferiores (grupo terapêutico, $\mathrm{n}=57$ ) e pacientes com indicação de profilaxia de tromboembolismo venoso (TEV), após cirurgias vasculares de grande porte ou amputações maiores (grupo profilático, $\mathrm{n}=57$ ), foram randomizados para receber a enoxaparina sob teste (Heptron ${ }^{\mathrm{TM}}$ ) ou a droga padrão-ouro (Sanofi-Aventis). A atividade da enoxaparina foi mensurada pela análise diária da atividade antifator-Xa no pico de concentração plasmática das drogas. Foram coletados dados de ocorrência ou progressão de TVP/TEV, eventos adversos graves e sangramentos graves; e foram utilizados para a análise de eficácia e segurança clínica como objetivos secundários.

Resultados: grupo terapêutico: 25 pacientes receberam enoxaparina genérica, e 32, a droga padrão-ouro (via subcutânea, $1 \mathrm{mg} / \mathrm{kg}$, a cada 12 horas). Os percentuais médios de atividade antifator-Xa dentro dos limites terapêuticos foram de $62 \pm 35,4 \%$ e $67,5 \pm 24,7 \%$, respectivamente $(p=0,035$, para não inferioridade). Nenhum paciente apresentou progressão da TVP, embolia pulmonar clinicamente detectável ou sangramentos maiores. Grupo profilático: trinta pacientes receberam enoxaparina genérica, e 27, a droga padrão-ouro (via subcutânea, $40 \mathrm{mg} / \mathrm{dia}$ ). Os percentuais médios de atividade antifator-Xa dentro dos limites terapêuticos foram de $77,9 \pm 30.9 \%$ e $77,8 \pm 32,9 \%$, respectivamente ( $\mathrm{p}$ $=0,009$, para não inferioridade). Nenhum paciente desenvolveu TVP ou apresentou sangramentos maiores.

Conclusão: enoxaparinas genéricas e de marca apresentaram respostas semelhantes em estudos in vivo, quan- 
do medidas pela atividade do anti-fator Xa, assim como eficácia clínica e dados de segurança similares.

Palavras-chave: ensaio clínico controlado, enoxaparina, medicamentos biossimilares.

\section{References}

1. Leizorovicz A, Simmonneau G, Decousus J, et al. Comparison of efficacy and safety of low molecular weight heparins and unfractionated heparin in initial treatment of deep venous thrombosis: a meta-analysis. BMJ 1994;309:299-304.

2. Lensing AWA, Prins MH, Davidson BL, et al. Treatment of deep venous thrombosis with low-molecular-weight heparins. Arch Intern Med 1995;155:601-607.

3. Fareed J, Leong WL, Hoppensteadt DA, et al. Generic Low-Molecular-Weight Heparins: Some Practical Considerations. Semin Thromb Hemost 2004;(30):703-13.

4. Gehrie E, Laposata M. Test of the month: The chromogenic antifactor Xa assay. Am J Hematol. 2012;(87):194-196.

5. Rowan BO, Kuhl DA, Lee MD, et al. Anti-Xa levels in bariatric surgery patients receiving prophylactic enoxaparin. Obes Surg. 2008;18(2):162-6.
6. Enoxaparin. DRUGDEXTM System. Greenwood Village, CO:Thomson Micromedex, 2006 Feb.http://www.thomsonhc.com.(accessed december 2008)

7. Glauser BF, Vairo BC, Oliveira CPM, et al. Generic versions of enoxaparin available for clinical use in Brazilare similar to the original drug. J Thromb Haemost 2011; 9:1419-22.

8. Lima MA, de Farias EH, Gray A, et al. Structural and pharmacological profile of generic enoxaparins used inBrazil. Clin Appl Thromb Hemost. 2012;18(4):379-86.

9. Gomes M, Ramacciotti E, Henriques AC, et al. Generic versus branded enoxaparin in the prevention of venous thromboembolism following major abdominal surgery: report of an exploratory clinical trial. Clin Appl Thromb Hemost. 2011;17(6):633-9.

10. Lage SG, Carvalho RT, Kopel L, et al. Safety and efficacy of sodium enoxaparin in anti-thrombotic prophylaxis and treatment. Rev Bras Ter Intensiva. 2007;19(1):67-73.

11. Bara L, Planes A, Samama MM. Occurrence of thrombosis and haemorrhage, relationship with anti-Xa, anti-IIa activities, and D-dimer plasma levels in patients receiving a low molecular weight heparin, enoxaparin or tinzaparin, to prevent deep vein thrombosis after hip surgery. Br J Haematol. 1999;104(2):230-40.

12. Mommertz G, Sigala F, Glowka TR, et al. Differences of venous thromboembolic risks in vascular general and trauma surgery patients. J Cardiovasc Surg (Torino). 2007;48(6):727-33

13. Matielo MF, Presti C, Casella IB, et al. Incidence of ipsilateral postoperative deep venous thrombosis in the amputated lower extremity of patients with peripheral obstructive arterial disease. J Vasc Surg. 2008;48(6):1514-9. 